ARTICLE

https://doi.org/10.1038/s41467-019-12312-4

\title{
Boosting selective nitrogen reduction to ammonia on electron-deficient copper nanoparticles
}

\author{
Yun-Xiao Lin (1) 1, Shi-Nan Zhang (1) 1, Zhong-Hua Xue', Jun-Jun Zhang (1) 1, Hui Su (1) 1, Tian-Jian Zhao (1) 1, \\ Guang-Yao Zhai (ib) ${ }^{1}$, Xin-Hao Li (id ${ }^{1 \star}$, Markus Antonietti (i) ${ }^{2} \&$ Jie-Sheng Chen $^{1 \star}$
}

Production of ammonia is currently realized by the Haber-Bosch process, while electrochemical $\mathrm{N}_{2}$ fixation under ambient conditions is recognized as a promising green substitution in the near future. A lack of efficient electrocatalysts remains the primary hurdle for the initiation of potential electrocatalytic synthesis of ammonia. For cheaper metals, such as copper, limited progress has been made to date. In this work, we boost the $\mathrm{N}_{2}$ reduction reaction catalytic activity of $\mathrm{Cu}$ nanoparticles, which originally exhibited negligible $\mathrm{N}_{2}$ reduction reaction activity, via a local electron depletion effect. The electron-deficient $\mathrm{Cu}$ nanoparticles are brought in a Schottky rectifying contact with a polyimide support which retards the hydrogen evolution reaction process in basic electrolytes and facilitates the electrochemical $N_{2}$ reduction reaction process under ambient aqueous conditions. This strategy of inducing electron deficiency provides new insight into the rational design of inexpensive $\mathrm{N}_{2}$ reduction reaction catalysts with high selectivity and activity.

\footnotetext{
${ }^{1}$ School of Chemistry and Chemical Engineering, Shanghai Jiao Tong University, Shanghai 200240, P. R. China. ${ }^{2}$ Department of Colloid Chemistry, Max Planck Institute of Colloids and Interfaces, Wissenschaftspark Golm, Potsdam 14424, Germany. *email: xinhaoli@sjtu.edu.cn; chemcj@sjtu.edu.cn
} 
T he exploration of electrochemical $\mathrm{N}_{2}$ fixation into ammonia, sustainable fertilizers for crops or energy carriers in the hydrogen economy ${ }^{1,2}$, has drawn tremendous interest due to the gentle and ambient process and low energy requirements $s^{3-5}$. In nature, only certain nitrogenase bacteria are able to selectively break the nonpolar triple bond, which is the most important process in the natural nitrogen cycle ${ }^{6}$. Pioneering works applying various noble metal-based $\mathrm{N}_{2}$ reduction reaction (NRR) catalysts (e.g., $\mathrm{Au}, \mathrm{Pt}, \mathrm{Ru}, \mathrm{Ag})^{7-10}$ as well as several recent examples of transition metals ${ }^{11-15}$ and carbonaceous catalysts $^{16-18}$ have already demonstrated the extraordinary advantages of these heterogeneous electrocatalysts, although the overall efficiency remains unsatisfactory. Further exploring novel strategies to elevate the selectivity (Faradaic efficiency) to $\mathrm{NH}_{3}$ and production rates of NRR catalysts, which are inexpensive and abundant, still remains challenging but highly alluring for the possible decentral $\mathrm{NH}_{3}$ generation on any scale under mild conditions.

Here, we report an effective strategy to boost the NRR activity of less active copper nanocatalysts via modulating the electron density of $\mathrm{Cu}$ nanoparticles over a significant potential scale to simultaneously depress the hydrogen evolution reaction (HER) activity and elevate the NRR activity for a higher Faradaic efficiency and yield rate of $\mathrm{NH}_{3}\left(17.2 \mu \mathrm{g} \mathrm{h}^{-1} \mathrm{~cm}^{-2}\right)$ in addition to a turnover frequency (TOF) value of $0.26 \mathrm{~h}^{-1}$. Textural analysis sufficiently demonstrates that the Mott-Schottky effect ${ }^{19-23}$ leads to an electron redistribution at the interface of polyimide (PI) $)^{24}$ and copper and thus controls the work functions of $\mathrm{Cu}$ species for more feasible $\mathrm{N}_{2}$ reduction, giving rise to a new high TOF value of $0.26 \mathrm{~h}^{-1}$, which is higher than that of noble metal-based NRR catalysts.

\section{Results}

Fabrication and structure of $\mathbf{C u} / \mathbf{P I}$ catalysts. The synthetic process for the $\mathrm{Cu} / \mathrm{PI}$ catalysts is depicted in Fig. 1a (for experimental details, please see the Methods). A modified solvothermal method was applied to prepare PI nanoflowers, which were further condensed at $300^{\circ} \mathrm{C}$ (PI-300), $400^{\circ} \mathrm{C}$ (PI-400) and $600{ }^{\circ} \mathrm{C}$ (PI-600) to tailor the conjugating degrees and used as supports for depositing $\mathrm{Cu}$ nanoparticles via a wet impregnation method $^{23}$. The color change in the PI supports from deep yellow to black directly reflects the gradually narrowed band structures, which have been further confirmed by their UV-vis spectra (Fig. 1b). The chemical structure of the PI support was verified by solid-state nuclear magnetic resonance (SSNMR) spectroscopy (Supplementary Fig. 1). After the introduction of $\mathrm{Cu}$ components, the flower-like morphology (Fig. 1b inset) of the PI supports with the thin nanosheets as the primary subunits remains unchanged, as revealed by the scanning electron microscopy (SEM) (Supplementary Fig. 2) and transmission electron microscopy (TEM) observation (Fig. 1c and Supplementary Fig. 3-5), as did the chemical structure as confirmed by the Fourier transform infrared (FT-IR) analysis (Supplementary Fig. 6). TEM (Fig. 1c) and highangle annular dark-field (HAADF) (Fig. 1d) images further demonstrate the integration of $\mathrm{Cu}$ nanoparticles inside the PI flower. The similar mean sizes of $\mathrm{Cu}$ nanoparticles around $30 \mathrm{~nm}$ (Supplementary Fig. 7) for all Cu/PI samples exclude possible size effect on their catalytic activity. Further Energy dispersive X-ray (EDX) mapping (Fig. 1d insert) images exhibit the homogenous distribution of $\mathrm{N}$ and $\mathrm{O}$ atoms along the PI supports and also verify the formation of $\mathrm{Cu}$-containing nanoparticles. A typical crystalline lattice distance of $0.2 \mathrm{~nm}$ (Fig. 1e), attributed to the (111) facet of metallic $\mathrm{Cu}$, further confirmed by its X-ray diffraction (XRD) patterns (Supplementary Fig. 8), prove the coexistence of $\mathrm{Cu}$ and PI in the $\mathrm{Cu} / \mathrm{PI}$ samples. X-ray photoelectron spectrum (XPS) results (Supplementary Fig. 9) not only provide a chemical composition of $\mathrm{Cu} / \mathrm{PI}$ containing only $\mathrm{C}, \mathrm{N}, \mathrm{O}$ and $\mathrm{Cu}$ but also exclude the presence of lattice oxygen in possible copper oxides or hydroxides (Supplementary Fig. 10).

$\mathrm{N}_{2}$ reduction reaction performance of $\mathrm{Cu} / \mathrm{PI}$ catalysts. We initially examined the possibility of the $\mathrm{Cu} / \mathrm{PI}$ hybrids for use as NRR electrocatalysts in basic solution $(0.1 \mathrm{M} \mathrm{KOH})$ at room temperature. At first glance, the $\mathrm{Cu} / \mathrm{PI}$ electrode (exemplified with $\mathrm{Cu} / \mathrm{PI}-300$ materials) offered a larger current density in $\mathrm{N}_{2}$ flow than the reference measurement in Ar (Fig. 2a), revealing a possible selectivity towards $\mathrm{N}_{2}$ reduction. Indeed, a standard electrocatalytic reaction over the $\mathrm{Cu} / \mathrm{PI}-300$ electrode with an optimized $\mathrm{Cu}$ content of 5\% (Supplementary Fig. 11 and Table 1-2) resulted in the best NRR Faradaic efficiency of $6.56 \%$ at a potential of $-0.3 \mathrm{~V}$ vs. RHE (Fig. $2 \mathrm{~b}$ and Supplementary Fig. 12). Carbon cloth (current collector), bare PI-300 electrode (Fig. 2b) and $\mathrm{CuO}_{\mathrm{x}} / \mathrm{PI}$-based electrode (Supplementary Table 2) were inert under the given conditions. It should be noted that the yields of ammonia were determined by both colorimetric method (Supplementary Fig. 13) and ion chromatography method (Supplementary Fig. 14). ${ }^{15} \mathrm{~N}$ isotope labeling experiments (Fig. 2a insert and Supplementary Fig. 15) confirm the electrocatalytic reduction process of the $\mathrm{N}_{2}$ gas over the $\mathrm{Cu} / \mathrm{PI}-300$ electrode into corresponding ammonia.

The mass loadings of $\mathrm{Cu} / \mathrm{PI}-300$ on the carbon cloth also slightly change the Faradaic efficiencies and the $\mathrm{NH}_{3}$ yield rates, and this condition was optimized as $5 \mathrm{mg} \mathrm{cm}^{-2}$ to afford the highest Faradaic efficiency $(6.56 \%)$ and $\mathrm{NH}_{3}$ yield rate $\left(12.4 \mu \mathrm{g} \mathrm{h}^{-1} \mathrm{~cm}^{-2}\right.$ ) at a potential of $-0.3 \mathrm{~V}$ vs. RHE (Fig. $2 \mathrm{c}$ and Supplementary Fig. 16). Cu/C catalyst (Supplementary Fig. 12), as a control sample of $\mathrm{Cu}$ nanoparticles prepared from the same method with $\mathrm{Cu} / \mathrm{PI}$, provide a Faradaic efficiency of only $0.17 \%$ (Fig. 2b) and a rather low yield rate of $\mathrm{NH}_{3}\left(\sim 0.7 \mu \mathrm{g} \mathrm{h}^{-1} \mathrm{~cm}^{-2}\right)$ (Supplementary Table 2), attesting to the essential contribution of the $\mathrm{Cu} / \mathrm{PI}$ combination to the high selectivity to NRR. The $\mathrm{NH}_{3}$ yield rate of the $\mathrm{Cu} / \mathrm{PI}-300$ electrode with a catalyst loading of 5 $\mathrm{mg} \mathrm{cm}{ }^{-2}$ could be further elevated to $17.2 \mu \mathrm{g} \mathrm{h}^{-1} \mathrm{~cm}^{-2}$ at an optimized potential of $-0.4 \mathrm{~V}$ vs. RHE (Fig. $2 \mathrm{~d}$ and Supplementary Fig. 17).

Effect of electron deficient $\mathrm{Cu}$. To understand the supporting effect on the NRR activity of supported $\mathrm{Cu}$ nanoparticles, we calculated the electronic structures of $\mathrm{Cu}$ clusters on PI and carbon supports via density functional theory (DFT) simulation. The electron density difference (EDD) (Fig. 3a, b) and Hirshfeld charge (Supplementary Fig. 18) results illustrate that the PI as a semiconductor support could attract more electrons from the $\mathrm{Cu}$ cluster $(0.06$ for each $\mathrm{Cu}$ atom $)$ than that by carbon support $(0.02$ for each $\mathrm{Cu}$ atom) in $\mathrm{Cu} / \mathrm{C}$ model, indicating a rectifying contact between $\mathrm{Cu}$ and PI semiconductors. Indeed, the programable band structures of PI-300, PI-400 and PI-600 samples (Fig. 3c) were further estimated on the basis of ultraviolet photoelectron spectroscopy (UPS) results (Supplementary Fig. 19), UV-vis absorption spectra (Fig. 1b and Supplementary Fig. 20) and Mott-Schottky plots (Supplementary Fig. 21). The thermal condensation process largely elevated the valence band positions of PI supports for PI-300 and PI-400 with higher synthetic temperatures, while their conduction bands were slightly elevated simultaneously. As presented by the SSNMR and FT-IR results (Supplementary Fig. 1 and 6), the PI-600 sample was highly condensed into organic carbons with a narrower band gap and also an improved conductivity. Accordingly, the estimated work functions of the PI supports decrease from PI-300 via PI-400 to PI-600. It is thus reasonable that PI-300 could attract more electrons from the deposited $\mathrm{Cu}$ nanoparticles due to the 
a

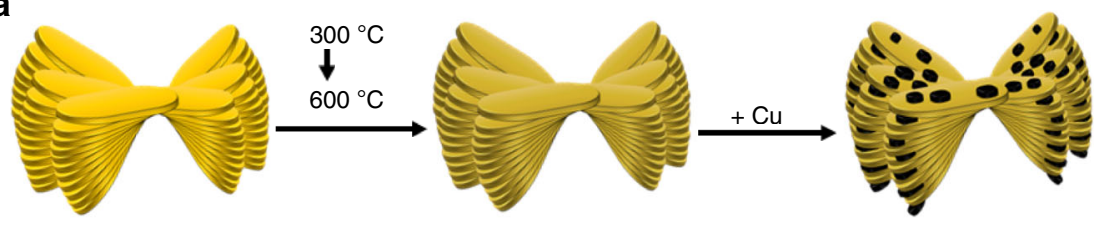

b
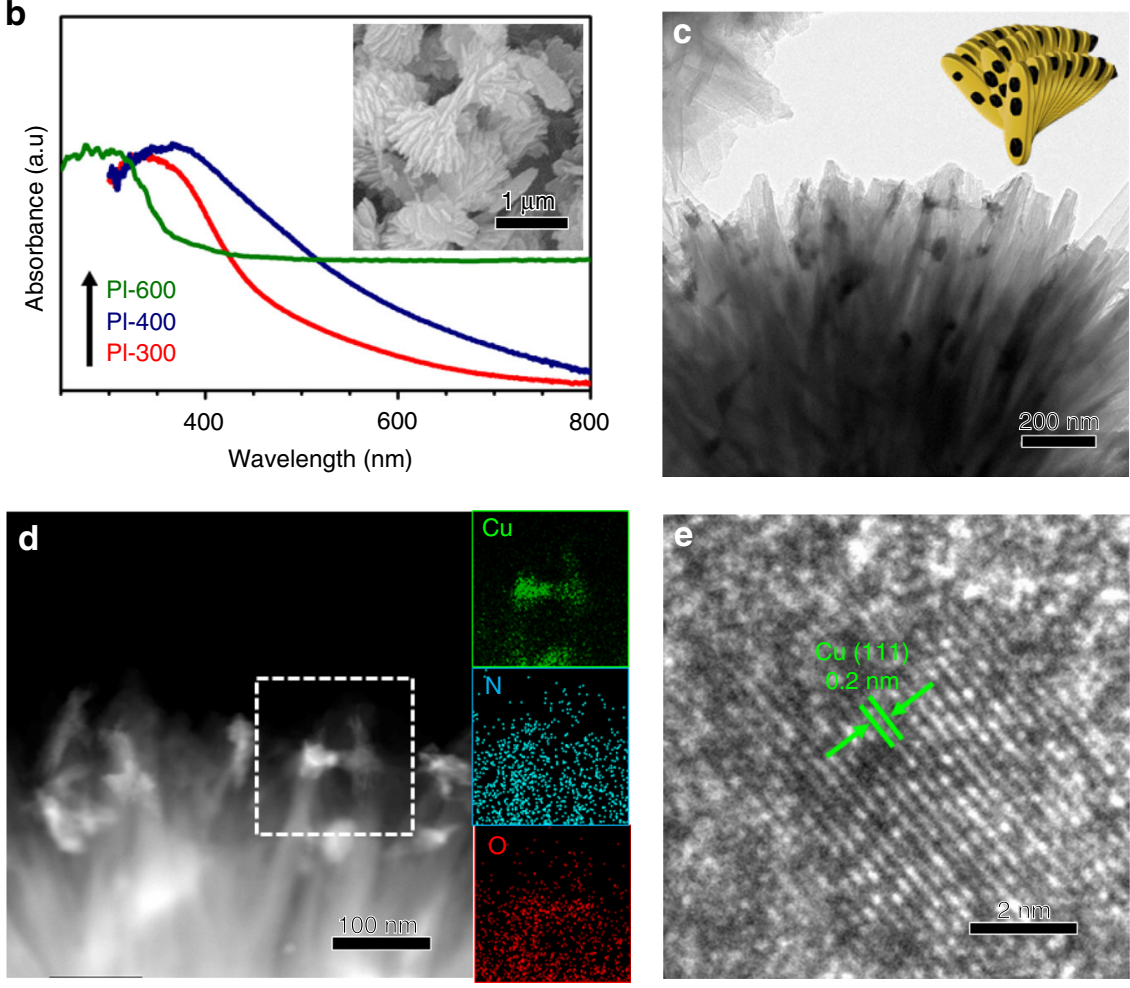

Fig. 1 Fabrication and structure of catalysts. a Synthetic procedure of typical Cu/PI catalyst. b Ultraviolet-visible (UV-vis) spectra of bare PI samples. Transmission electron microscopy (TEM) c, high-angle annular dark-field (HAADF) d, and high-resolution TEM (HRTEM) e images of Cu/PI-300. Insets: b Scanning electron microscopy (SEM) image of PI-300; d Energy dispersive X-yay (EDX) mapping images of the selected area

rectifying Mott-Schottky effect ${ }^{25,26}$ at the $\mathrm{Cu} / \mathrm{PI}$ interface, which was reflected by the greatly enhanced work function of $\mathrm{Cu}$ in $\mathrm{Cu} /$ PI-300 (Fig. 3d) estimated from the UPS analysis results (Supplementary Fig. 22). Furthermore, the gradual shifts of typical $\mathrm{Cu}$ $2 \mathrm{p}_{3 / 2}$ XPS peaks (Fig. 3e) to higher energy was attributed to the gradually increased numbers of electrons donated by $\mathrm{Cu}$ particles of the PI supports with even higher work functions (Fig. 3d). It doubly verified that PI-300 could attract more electrons from the deposited $\mathrm{Cu}$ nanoparticles according to the larger shift of $\mathrm{Cu}$ $2 \mathrm{p}_{3 / 2}$ XPS peak for Cu/PI-300 (Fig. 3e). It should be noted that the typical $\mathrm{Cu} 2 \mathrm{p}_{3 / 2}$ peaks of copper oxides was estimated to be centered at $935.0 \mathrm{eV}$ (data not shown), directly excluding the presence of $\mathrm{CuO}$ as the main component in all $\mathrm{Cu} / \mathrm{PI}$ samples. The gradually decreased electron density in metallic $\mathrm{Cu}$ in $\mathrm{Cu} / \mathrm{PI}$ samples from $\mathrm{Cu} / \mathrm{PI}-600$ to $\mathrm{Cu} / \mathrm{PI}-300$ (Fig. 3d, e) again confirm that $\mathrm{Cu}$ is the electron donor, as depicted in the right side of Fig. 3c, making the $\mathrm{Cu}$ nanoparticles more "noble".

Density functional theory calculations. We next carefully analyzed the actual role of the electron deficiency of $\mathrm{Cu}$ nanoparticles in activating $\mathrm{N}_{2}$ molecules and boosting their NRR activity. The polarization of adsorbed $\mathrm{N}_{2}$ molecules was gradually enhanced by $\mathrm{Cu}$ surface with lowered electronic density which was well presented by the obvious differences in the electron density difference (Fig. $3 \mathrm{f}$ insert) and Hirshfeld charge (Supplementary Fig. 23) of each $\mathrm{N}$ atom after changing the catalytic surface from the pristine $\mathrm{Cu}$ to the electron-deficient $\mathrm{Cu}\left(\mathrm{Cu}-0.04 \mathrm{e}^{-}\right.$and $\mathrm{Cu}-$ $0.06 \mathrm{e}^{-}$) models. The strengthened interaction with $\mathrm{N}_{2}$ on $\mathrm{Cu}$ surface with lowered electronic density was also well reflected by the enhanced adsorption energy (Fig. 3f). Such a strong interaction between $\mathrm{N}_{2}$ and $\mathrm{Cu} / \mathrm{PI}$ dyads was further confirmed by the $\mathrm{N}_{2}$ adsorption-desorption and $\mathrm{N}_{2}$-TPD analysis results (Fig. $3 \mathrm{~g}$ and Supplementary Fig. 24-25). More pronounced electrondeficiency of $\mathrm{Cu}$ nanoparticles from $\mathrm{Cu} / \mathrm{PI}-600$ via $\mathrm{Cu} / \mathrm{PI}-400$ to $\mathrm{Cu} / \mathrm{PI}-300$ leads to gradually increased $\mathrm{N}_{2}$ adsorption capacities for 0.6, 2.6 and 4.1 times as compared to the values of corresponding bare PI supports (Supplementary Fig. 25c). The lowest surface area of Cu/PI-300 among all Cu/PI samples (Supplementary Fig. 24) directly demonstrate the main contribution of electron-deficient $\mathrm{Cu}$ to its high $\mathrm{N}_{2}$ adsorption capacity.

Moreover, depressing the HER process during NRR is another aspect to ensure the final selectivity of a catalyst. For the HER process in basic electrolyte conditions, the adsorption of water molecules and desorption of $\mathrm{OH}^{-}$usually dominate the entire mass transfer process. An electron-deficient surface of $\mathrm{Cu}$ nanoparticles obviously generates a strong electrostatic interaction with the $\mathrm{OH}^{-}$anions (Fig. 3h inset), which is undesirable for HER on the $\mathrm{Cu}$-centers in base solution. As a result, $\mathrm{Cu} / \mathrm{PI}-300$ exhibited the worst HER performance (Fig. 3h) among all $\mathrm{Cu} / \mathrm{PI}$ samples in this work. The much higher Tafel slope for HER over the Cu/PI-300 catalyst compared with other controls 

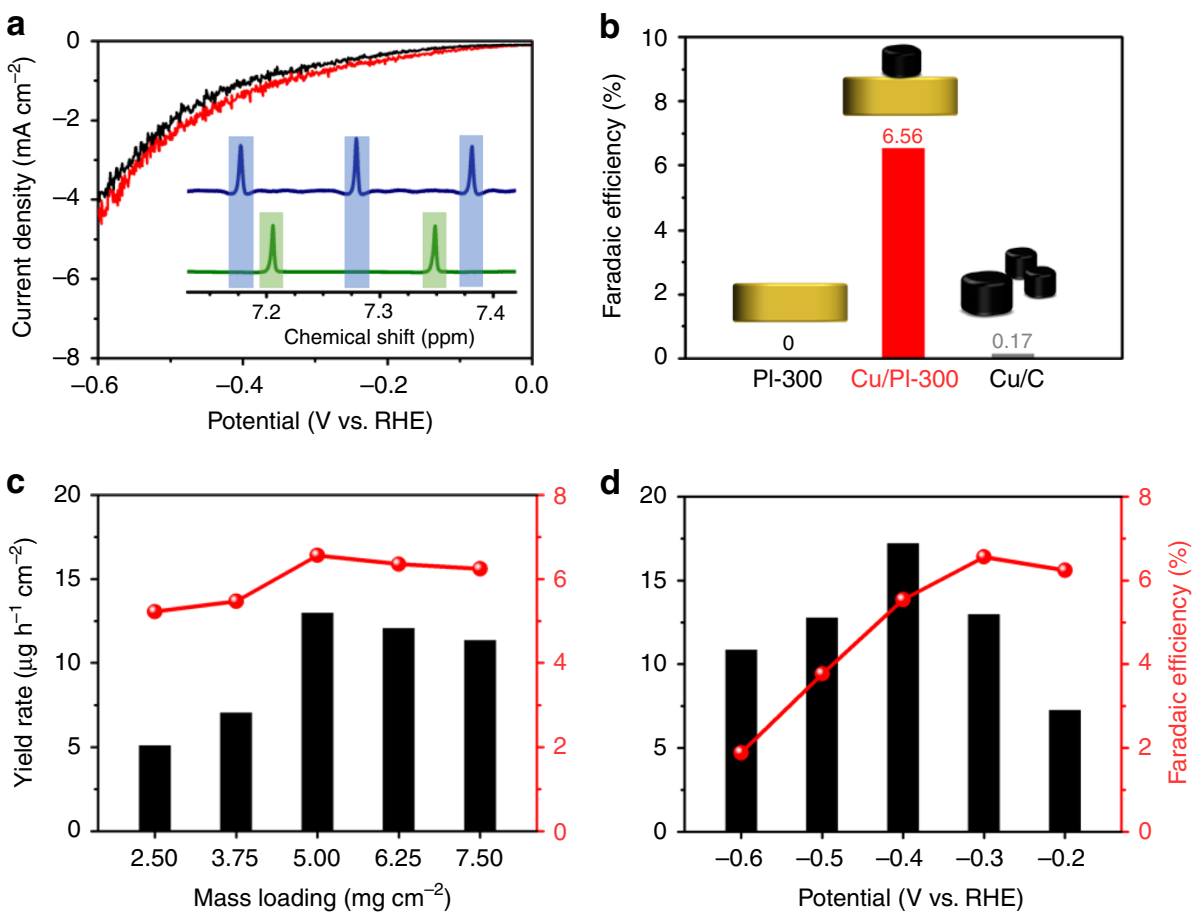

Fig. $2 \mathrm{~N}_{2}$ reduction reaction performance of the electrocatalysts. a The linear sweep voltammogram (LSV) curves of Cu/PI-300 (catalyst loading: $5 \mathrm{mg} \mathrm{cm}^{-2}$ ) measured at a scan rate of $10 \mathrm{mV} \mathrm{s}^{-1}$ under the Ar and $\mathrm{N}_{2}$ atmosphere. $\mathbf{b}$ The Faradaic efficiencies of bare PI-300, Cu/PI-300, and $\mathrm{Cu} / \mathrm{C}$ for $\mathrm{NH}_{3}$ generation at $-0.3 \mathrm{~V}$ vs. RHE within $6 \mathrm{~h}$. The Faradaic efficiencies (spheres) and $\mathrm{NH}_{3}$ yield rates (bars) of $\mathrm{Cu} / \mathrm{PI}-300$ with varied catalyst loadings at $-0.3 \mathrm{~V}$ vs. RHE c or with a fixed catalyst loading $\left(5 \mathrm{mg} \mathrm{cm}^{-2}\right)$ at different work potentials d within $6 \mathrm{~h}$. Insets: a ${ }^{1} \mathrm{H} \mathrm{NMR} \mathrm{spectra} \mathrm{of} \mathrm{both}{ }^{14} \mathrm{NH}_{4}{ }^{+}$and ${ }^{15} \mathrm{NH}_{4}+$ produced from the NRR reaction using ${ }^{14} \mathrm{~N}_{2}$ and ${ }^{15} \mathrm{~N}_{2}$ gas respectively

(Supplementary Fig. 26) directly confirm the negative effect of the electron-deficiency induced in the $\mathrm{Cu}$ nanoparticles on HER, which is, on the other hand, highly preferred for the improvement of NRR performance for gradually elevated ammonia yields (Fig. 3i). More importantly, the addition of first hydrogen atom to pre ${ }^{-}$adsorbed $\mathrm{N}_{2}\left({ }^{*} \mathrm{~N}_{2}\right)$ as the rate ${ }^{-}$limiting step and the following steps, according to the calculated Gibbs free energy change $(\Delta \mathrm{G})$ of the NRR (Fig. 4a and S27) are also gradually facilitated by the $\mathrm{Cu}$ clusters with even lower electronic density as reflected by the remarkably lowered $\Delta \mathrm{G}$ (from $2.30 \mathrm{eV}$ on pristine $\mathrm{Cu}$ via $1.76 \mathrm{eV}$ on $\mathrm{Cu}-0.04 \mathrm{e}^{-}$to $1.60 \mathrm{eV}$ on $\left.\mathrm{Cu}-0.06 \mathrm{e}^{-}\right)$. The dissociation step from ${ }^{\star} \mathrm{NNH}_{4}$ to ${ }^{\star} \mathrm{NH}_{2}$ proceed automatically again due to the largely reduced free energy by the electrondefecient $\mathrm{Cu}$ surface.

Both experimental and theoretical results demonstrate the key effect of electron density of metallic $\mathrm{Cu}$ nanoparticles on the promoted NRR process. As a results, the $\mathrm{Cu} / \mathrm{PI}-300$ nanocomposite containing electron-deficient $\mathrm{Cu}$ nanoparticles is the first example of $\mathrm{Cu}$-based nanocatalysts for electrochemical NRR with a Faradaic efficiency of 6.56\%, while CuS (Supplementary Fig. 28), as the best-in-class $\mathrm{Cu}$-based NRR catalyst in the literature, yields a Faradaic efficiency of only $0.18 \%{ }^{27}$. Furthermore, the $\mathrm{NH}_{3}$ generation yield rate of Cu/PI-300 $\left(17.2 \mu \mathrm{g} \mathrm{h}^{-1} \mathrm{~cm}^{-2}\right)$ is also among the highest levels reported for state-of-the-art NRR electrocatalysts, far surpassing the reported Cu-based NRR electrocatalyst and comparable to noble metal-based counterparts (Fig. $4 \mathrm{~b}$ and Supplementary Table 3 ). It should be noted that utilization of more noble $\mathrm{Cu}$ nanoparticles as the catalytically active centers in $\mathrm{Cu} / \mathrm{PI}-300$ provides a TOF value of $0.26 \mathrm{~h}^{-1}$ for NRR, outpacing that of the traditional noble metal-based NRR electrode in the three-electrode system ${ }^{7}$.

Catalytic stability. The rectifying contact at the highly coupled interface of $\mathrm{Cu}$ and PI also ensures the electrochemical stability of the Cu/PI-300 catalyst for long-term NRR processes. The flat and repeatable i-t curves at $-0.4 \mathrm{~V}$ vs. RHE in $0.1 \mathrm{~mol} \mathrm{~L}^{-1} \mathrm{KOH}$ (Fig. 4c) exhibited negligible attenuation after a 30 -h run of standard NRR reactions with the electrolyte renewed every $6 \mathrm{~h}$. The excellent durability of the catalytic active species in the $\mathrm{Cu} /$ PI-300 catalyst were also further indicated by the stable $\mathrm{NH}_{3}$ yield rates, TOF values (Fig. 4d), and Faradaic efficiencies (Supplementary Fig. 29) for the following four runs of the recycling test. This is especially remarkable as ammonia is known to etch bulk copper to form stable amine-complexes.

\section{Discussion}

In conclusion, herein we present and describe success in designing electron-deficient $\mathrm{Cu}$ nanoparticles on semiconductive PI for application as inexpensive but effective metal catalysts to reduce gaseous dinitrogen under ambient conditions. Importantly, the Mott-Schottky interface contact between the metal and semiconductor tunes the electron density of $\mathrm{Cu}$ nanoparticles for preferred adsorption of $\mathrm{OH}^{-}$in basic solution to inhibit the HER process. Simultaneously, electron-deficient $\mathrm{Cu}$ nanoparticles remarkably enhance the pre-adsorption of $\mathrm{N}_{2}$ molecules for an improved $\mathrm{NH}_{3}$ generation yield, as visible even in $\mathrm{N}_{2}$-TPD. The present result opens new directions in the search for Mott-Schottky catalysts, using inexpensive and common metals and supports to improve and optimize the specific reaction from impossible to high yield, and resulting in a de novo breakthrough for $\mathrm{Cu}$-catalyzed NRR and a design guideline for other inexpensive metal-based Mott-Schottky catalysts.

\section{Methods}

Preparation of PI nanoflower. PI nanoflower was synthesized by following a previously reported procedure ${ }^{28}$. In a $250 \mathrm{~mL}$ beaker, 1,4-diaminobenzene $(1.08 \mathrm{~g}$, $100 \mathrm{mmol}$ ) was dissolved into DMF (anhydrous, $60 \mathrm{~mL}$ ) solution before benzene- 
a

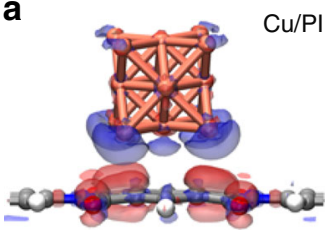

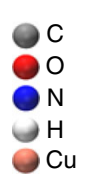

b

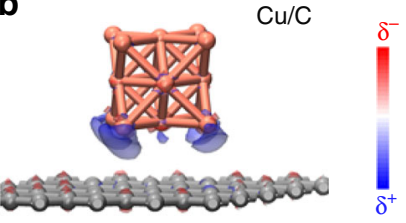

C
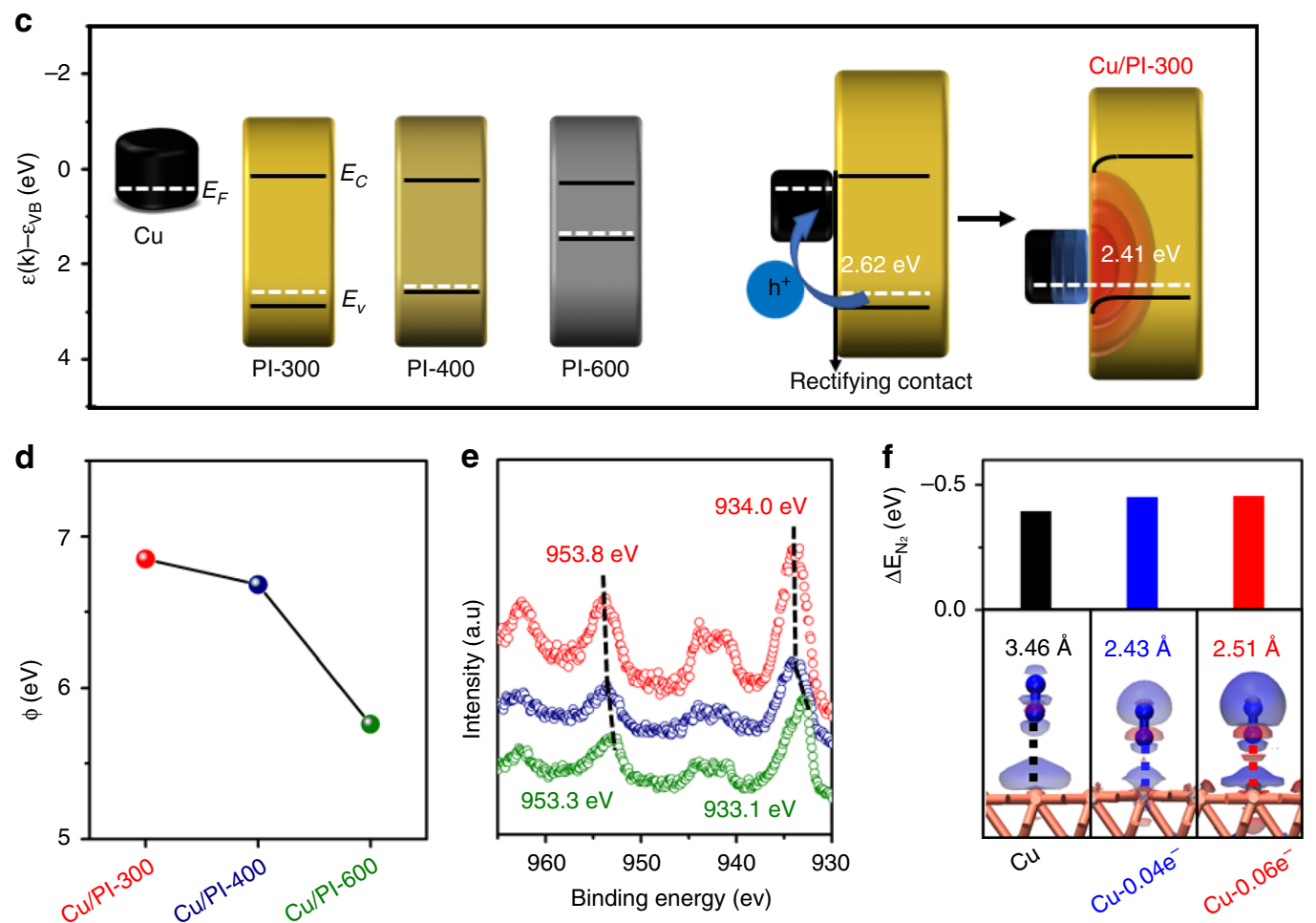

g

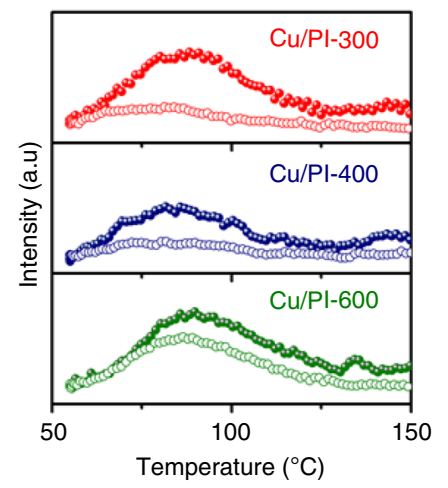

h

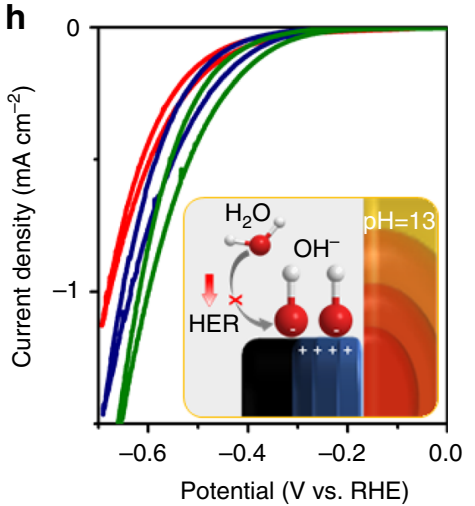

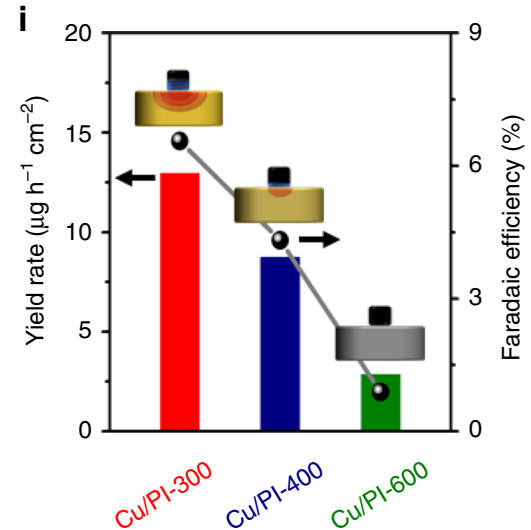

Fig. 3 Effect of electron deficient $\mathrm{Cu}$ nanoparticles on the catalytic performance. EDD stereograms of a $\mathrm{Cu} / \mathrm{PI}$ and $\mathbf{b} \mathrm{Cu} / \mathrm{C}$ models. $\mathbf{c}$ Experimentally estimated work functions and band structures of $\mathrm{Cu}$ and $\mathrm{PI}$ components (left) and schematic diagram of rectifying contact of $\mathrm{Cu}$ and PI hybrid (right), resulting in electron rich (red) and deficient (blue) areas at their interface. The estimated work functions from UPS analysis $\mathbf{d}$ and X-ray photoelectron spectroscopy (XPS) Cu 2p spectra e of Cu/PI samples. $\mathbf{f}$ The calculated adsorption energies of $\mathrm{N}_{2}$ molecules on pristine $\mathrm{Cu}(\mathrm{Cu}$ ) and electron-deficient $\mathrm{Cu}$ ( $\mathrm{Cu}-0.04 \mathrm{e}^{-}$and $\mathrm{Cu}-0.06 \mathrm{e}^{-}$) surface. $\mathbf{g}$ The $\mathrm{N}_{2}$-temperature programmed desorption (TPD) results of $\mathrm{Cu} / \mathrm{PI}$ catalysts (spheres) and corresponding bare PI supports (circles). $\mathbf{h}$ The cyclic voltammograms (CVs) of $\mathrm{Cu} / \mathrm{PI}$ electrodes (catalyst loading: $1 \mathrm{mg} \mathrm{cm}^{-2}$ ) at a scan rate of $5 \mathrm{mV} \mathrm{s}^{-1}$ in Ar-saturated $0.1 \mathrm{M}$ $\mathrm{KOH}$. i The $\mathrm{NH}_{3}$ yield rates and Faradaic efficiencies of $\mathrm{Cu} / \mathrm{PI}$ electrodes at $-0.3 \mathrm{~V}$ vs. RHE. Insets: $\mathbf{f}$ EDD stereograms of $\mathrm{N}_{2}$ molecules on pristine $\mathrm{Cu}$ (Cu) and electron-deficient $\mathrm{Cu}\left(\mathrm{Cu}-0.04 \mathrm{e}^{-}\right.$and $\left.\mathrm{Cu}-0.06 \mathrm{e}^{-}\right)$surface. $\mathbf{h}$ the deactivation mechanism of the HER process over electron deficient $\mathrm{Cu}$ nanoparticles in $\mathrm{Cu} / \mathrm{PI}-300 ;$ i proposed electron localization at the $\mathrm{Cu}-\mathrm{PI}$ boundaries

1,2,4,5-tetracarboxylic dianhydride $(2.18 \mathrm{~g}, 100 \mathrm{mmol})$ was added with stirring. The reaction was kept overnight until the viscosity stopped increasing. Then, $30 \mathrm{~mL}$ of the solution was transferred into a Teflon-inner autoclave to further polymerization at $180^{\circ} \mathrm{C}$ for $10 \mathrm{~h}$. After cooling down, the precipitate in the autoclave was filtrated and washed with DMF and ethanol for several times. The obtained yellowish solid was dried in vacuum overnight and grounded into fine powder. The powder were then heated to 300,400 , or $600^{\circ} \mathrm{C}$ at a rate of $5^{\circ} \mathrm{C} / \mathrm{min}$ and maintained at that temperature for $8 \mathrm{~h}$ in a tube furance with $\mathrm{N}_{2}$ flow to generate PI-300, PI-400 or PI-600, respectively.

Preparation of $\mathbf{C u} / \mathbf{P I}$ catalyst and $\mathbf{C u} / \mathbf{C}$ catalyst. $100 \mathrm{mg}$ of PI-300, PI-400, PI600 , or carbon black and $19 \mathrm{mg} \mathrm{Cu}\left(\mathrm{NO}_{3}\right)_{2} \cdot 3 \mathrm{H}_{2} \mathrm{O}$ were dispersed into $8 \mathrm{~mL}$ of water via sonication and vigorous stir for $2 \mathrm{~h} .200 \mu \mathrm{L} 1 \mathrm{M} \mathrm{NaOH}$ solution was added to the 

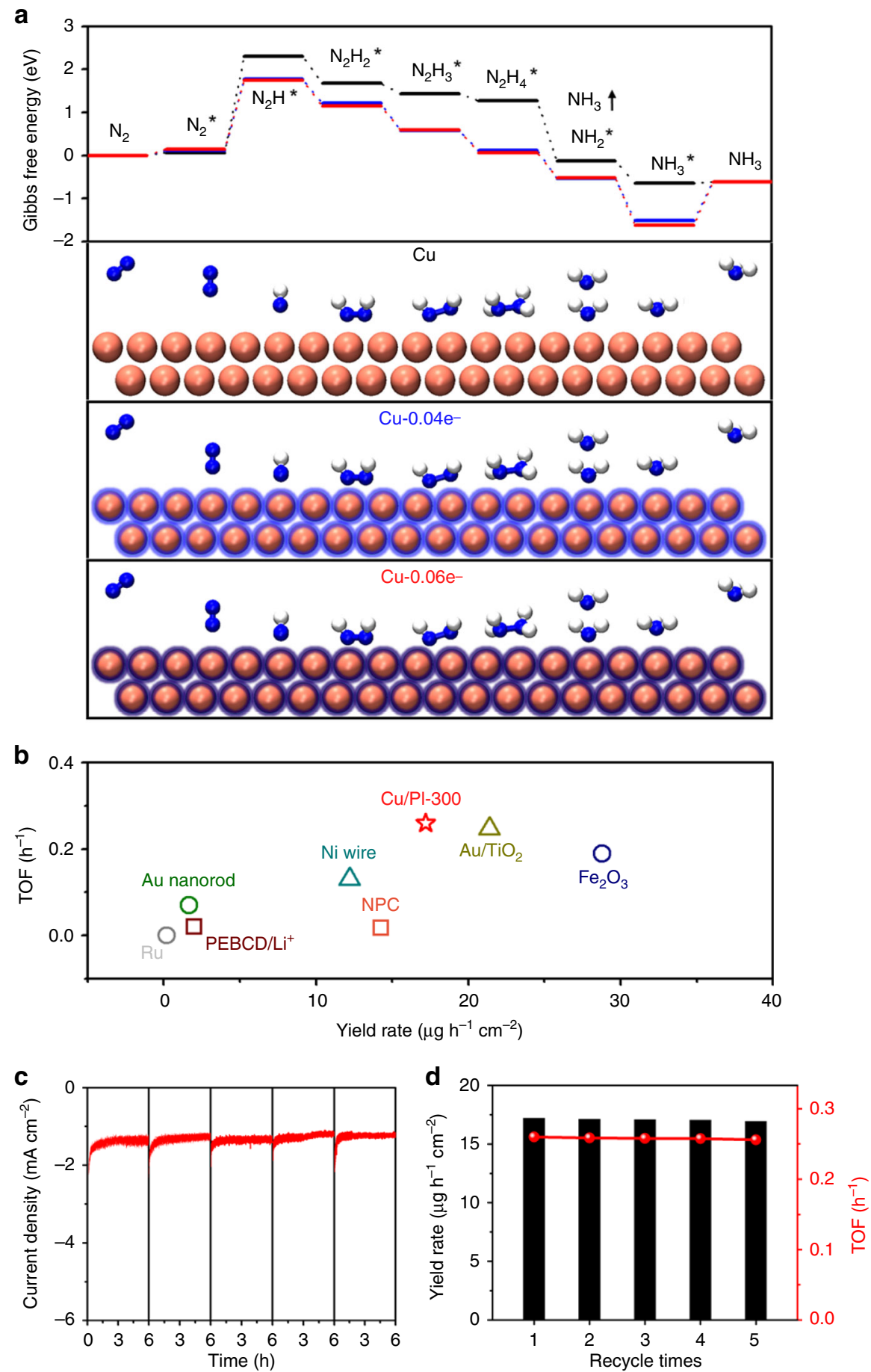

Fig. 4 Density functional theory calculations and stability. a Calculated absorption configurations (bottom) and corresponding Gibbs free energy diagrams of each step of NRR process on pristine $\mathrm{Cu}$ (black), $\mathrm{Cu}-0.04 \mathrm{e}^{-}$(blue) and $\mathrm{Cu}-0.06 \mathrm{e}^{-}$(red) models. $\mathbf{b}$ The turnover frequency (TOF) values and $\mathrm{NH}_{3}$ generation yield rates of $\mathrm{Cu} / \mathrm{PI}-300$ and benchmarked NRR electrocatalyst in the literature (details listed in Table S3). The i-t curves $\mathbf{c}$ of five runs of 6-h NRR reaction over a reused $\mathrm{Cu} / \mathrm{PI}-300$ at $-0.4 \mathrm{~V}$ vs. $\mathrm{RHE}$ and corresponding $\mathrm{NH}_{3}$ yield rates and TOF values d

solution before another two-hour stirring. And then, $0.5 \mathrm{~mL}$ of $1 \mathrm{M} \mathrm{NaBH}_{4}$ was added dropwise to this suspension. The obtained mixture was separated via centrifugation, washed thoroughly with distilled water and ethanol, then dried in vacuum at $60^{\circ} \mathrm{C}$ overnight. The powder was obtained as $\mathrm{Cu} / \mathrm{PI}-300, \mathrm{Cu} / \mathrm{PI}-400, \mathrm{Cu} / \mathrm{PI}-600$, or $\mathrm{Cu} / \mathrm{C}$.

Preparation of $\mathbf{C u O}_{\mathbf{x}} / \mathrm{PI}-\mathbf{3 0 0}$ catalyst. $100 \mathrm{mg}$ of PI-300 and $19 \mathrm{mg} \mathrm{Cu}$

$\left(\mathrm{NO}_{3}\right)_{2} \cdot 3 \mathrm{H}_{2} \mathrm{O}$ were dispersed into $8 \mathrm{~mL}$ of water via sonication and vigorous stir for 2 h. $200 \mu \mathrm{L} 1 \mathrm{M} \mathrm{NaOH}$ solution was added to the solution before another two-hour stirring. The obtained mixture was separated via centrifugation, washed thoroughly with distilled water, then dried in furnace at $100{ }^{\circ} \mathrm{C}$ overnight. The powder was obtained as $\mathrm{CuO}_{\mathrm{x}} / \mathrm{PI}-300$.
Preparation of $\mathrm{Cu} / \mathrm{PI} /$ carbon cloth electrodes. $20 \mathrm{mg}$ catalyst $(\mathrm{Cu} / \mathrm{PI}-300, \mathrm{Cu}$ / PI-400, or Cu/PI-600), $800 \mu \mathrm{L}$ of $\mathrm{H}_{2} \mathrm{O}, 800 \mu \mathrm{L}$ of EtOH and $280 \mu \mathrm{L}$ of $5 \mathrm{wt} \%$ Nafion solution in alcohol were mixed and sonicated to generate the catalyst ink. 230/350/ $470 / 590 / 700 \mu \mathrm{L}$ ink was dropped on the carbon cloth evenly at certain area $(1 \mathrm{~cm} \times$ $1 \mathrm{~cm}$ ) and then dried at room temperature to afford the $\mathrm{Cu} / \mathrm{PI} /$ carbon cloth electrodes for electrochemical NRR measurements with the mass loading of 2.50/ $3.75 / 5.00 / 6.25 / 7.50 \mathrm{mg} \mathrm{cm}^{-2}$, respectively.

Preparation of the reference carbon cloth electrodes. $20 \mathrm{mg}$ catalyst $(\mathrm{Cu} / \mathrm{C}$ or PI-300), $800 \mu \mathrm{L}$ of $\mathrm{H}_{2} \mathrm{O}, 800 \mu \mathrm{L}$ of EtOH and $280 \mu \mathrm{L}$ of $5 \mathrm{wt} \%$ Nafion solution in alcohol were mixed and sonicated to generate the catalyst ink. $470 \mu \mathrm{L}$ ink was 
dropped on the carbon cloth evenly at certain area $(1 \mathrm{~cm} \times 1 \mathrm{~cm})$ and then dried at room temperature to afford the reference cloth electrodes for electrochemical NRR measurements with the mass loading of $5.00 \mathrm{mg} \mathrm{cm}^{-2}$.

\section{Data availability}

The data that support the findings of this study are available from the corresponding authors upon request.

Received: 16 January 2019; Accepted: 29 August 2019;

Published online: 26 September 2019

\section{References}

1. Smil, V. Enriching The Earth: Fritz Haber, Carl Bosch, and The Transformation of World Food Production (MIT Press, London, UK, 2004).

2. Ritter, S. K. Chem. Eng. News 86, 53 (2008).

3. Qin, Q., Heil, T., Antonietti, M., \& Oschatz, M. Single-site gold catalysts on hierarchical $\mathrm{n}$-doped porous noble carbon for enhanced electrochemical reduction of nitrogen. Small Methods 2, 1800202 (2018).

4. Guo, C., Ran, J., Vasileff, A. \& Qiao, S. Z. Rational design of electrocatalysts and photo(electro)catalysts for nitrogen reduction to ammonia $\left(\mathrm{NH}_{3}\right)$ under ambient conditions. Energy Environ. Sci. 11, 45-56 (2018).

5. Montoya, J. H., Tsai, C., Vojvodic, A. \& Nørskov, J. K. The challenge of electrochemical ammonia synthesis: A new perspective on the role of nitrogen scaling relations. ChemSusChem 8, 2180-2186 (2015).

6. Smith, B. E. Nitrogenase reveals its inner secrets. Science 297, 1654-1655 (2002).

7. Shi, M. M. et al. Au sub-nanoclusters on $\mathrm{TiO}_{2}$ toward highly efficient and selective electrocatalyst for $\mathrm{N}_{2}$ conversion to $\mathrm{NH}_{3}$ at ambient conditions. $A d v$. Mater. 29, 1606550 (2017).

8. Kordali, V., Kyriacou, G. \& Lambrou, C. Electrochemical synthesis of ammonia at atmospheric pressure and low temperature in a solid polymer electrolyte cell. Chem. Commun. 17, 1673-1674 (2000).

9. Shi, M. M. et al.. Anchoring PdCu amorphous nanocluster on graphene for electrochemical reduction of $\mathrm{N}_{2}$ to $\mathrm{NH}_{3}$ under ambient conditions in aqueous solution. Adv. Energy Mater. 8, 1800124 (2018).

10. Lee, H. K. et al. Favoring the unfavored: selective electrochemical nitrogen fixation using a reticular chemistry approach. Sci. Adv. 4, eaar3208 (2018).

11. Kim, K. et al. Electrochemical synthesis of ammonia from water and nitrogen in ethylenediamine under ambient temperature and pressure. J. Electrochem. Soc. 163, 1523-1526 (2016).

12. Jeong, E.-Y. et al. Electrochemical ammonia synthesis mediated by titanocene dichloride in aqueous electrolytes under ambient conditions. ACS Sustain. Chem. Eng. 5, 9662-9666 (2017).

13. Zhang, L. et al.. Electrochemical ammonia synthesis via nitrogen reduction reaction on a $\mathrm{MoS}_{2}$ catalyst: theoretical and experimental studies. Adv. Mater. 30, 1800191 (2018)

14. Qiu, W. et al. High-performance artificial nitrogen fixation at ambient conditions using a metal-free electrocatalyst. Nat. Commun. 9, 3485 (2018).

15. Zhu, X. et al. Efficient and durable $\mathrm{N}_{2}$ reduction electrocatalysis under ambient conditions: $\beta$ - $\mathrm{FeOOH}$ nanorods as a non-noble-metal catalyst. Chem. Commun. 54, 11332-11335 (2018).

16. Liu, Y. et al. Facile ammonia synthesis from electrocatalytic $\mathrm{N}_{2}$ reduction under ambient conditions on N-doped porous carbon. ACS Catal. 8, 1186-1191 (2018).

17. Deng, J. \& Liu, C. Boron-doped graphene catalyzes dinitrogen fixation with electricity. Chem 4, 1773-1774 (2018).

18. Mukherjee, $\mathrm{S}$. et al. Metal-organic framework-derived nitrogen-doped highly disordered carbon for electrochemical ammonia synthesis using $\mathrm{N}_{2}$ and $\mathrm{H}_{2} \mathrm{O}$ in alkaline electrolytes. Nano Energy 48, 217-226 (2018).

19. Xue, Z.-H. et al. Janus Co/CoP nanoparticles as efficient Mott-Schottky electrocatalysts for overall water splitting in wide $\mathrm{pH}$ range. Adv. Energy Mater. 7, 1602355 (2017).

20. Su, H. et al. Activating cobalt nanoparticles via the Mott-Schottky effect in nitrogen-rich carbon shells for base-free aerobic oxidation of alcohols to esters. J. Am. Chem. Soc. 139, 811-818 (2017).

21. Hou, J. et al. Promoting active sites in core-shell nanowire array as Mott-Schottky electrocatalysts for efficient and stable overall water splitting. Adv. Funct. Mater. 28, 1704447 (2018)
22. Xue, Z.-H. et al. Tuning the adsorption energy of methanol molecules along Ni-N-doped carbon phase boundaries by the Mott-Schottky effect for gasphase methanol dehydrogenation. Angew. Chem. Int. Ed. 57, 2697-2701 (2018).

23. Cai, Y.-Y. et al. Highly efficient dehydrogenation of formic acid over a palladium-nanoparticle-based Mott-Schottky photocatalyst. Angew. Chem. Int. Ed. 52, 11822-11825 (2013).

24. Lin, Y.-X. et al. A polyimide nanolayer as a metal-free and durable organic electrode toward highly efficient oxygen evolution. Angew. Chem. Int. Ed. 57, 12563-12566 (2018).

25. Hou, Y. et al. Branched $\mathrm{WO}_{3}$ nanosheet array with layered $\mathrm{C}_{3} \mathrm{~N}_{4}$ heterojunctions and $\mathrm{CoO}_{\mathrm{x}}$ nanoparticles as a flexible photoanode for efficient photoelectrochemical water oxidation. Adv. Mater. 26, 5043-5049 (2014).

26. Li, X.-H. \& Antonietti, M. Metal nanoparticles at mesoporous $\mathrm{N}$-doped carbons and carbon nitrides: functional Mott-Schottky heterojunctions for catalysis. Chem. Soc. Rev. 42, 6593-6604 (2013).

27. Furuya, N. \& Yoshiba, H. Electroreduction of nitrogen to ammonia on gasdiffusion electrodes loaded with inorganic catalyst. J. Electroanal. Chem. 291 269-272 (1990).

28. Xu, Z. et al. Nitrogen-Doped Porous Carbon Superstructures Derived from Hierarchical Assembly of Polyimide Nanosheets. Adv. Mater. 28, 1981-1987 (2016).

\section{Acknowledgements}

This work was supported by the National Natural Science Foundation of China (21722103, 21720102002, and 21673140), the Shanghai Basic Research Program (16JC1401600), the SJTU-MPI partner group and the Shanghai Rising-Star Program (16QA1402100).

\section{Author contributions}

X.-H.L. and Y.-X.L. designed the experiments. Y.-X.L. conducted the synthesis of the Cu/ $\mathrm{Pi}$ catalysts and electrodes and carried out all of the corresponding characterizations and analysis. X.-H.L. and Y.-X.L. co-wrote the original manuscript. S.-N.Z. helped to conduct DFT calculations and results analysis. Z.-H.X., J.-J.Z., H.S., T.-J.Z and G.-Y.Z. help to conduct the electrochemical experiments. J.-S.C., M.A. and X.-H.L. oversaw all of the research phases and revised the manuscript. All of the authors discussed the results and commented on the manuscript.

\section{Competing interests}

The authors declare no competing interests.

\section{Additional information}

Supplementary information is available for this paper at https://doi.org/10.1038/s41467 019-12312-4.

Correspondence and requests for materials should be addressed to X.-H.L. or J.-S.C.

Peer review information Nature Communications thanks anonymous reviewers for their contributions to the peer review of this work.

Reprints and permission information is available at http://www.nature.com/reprints

Publisher's note Springer Nature remains neutral with regard to jurisdictional claims in published maps and institutional affiliations.

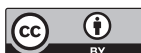

Open Access This article is licensed under a Creative Commons Attribution 4.0 International License, which permits use, sharing, adaptation, distribution and reproduction in any medium or format, as long as you give appropriate credit to the original author(s) and the source, provide a link to the Creative Commons license, and indicate if changes were made. The images or other third party material in this article are included in the article's Creative Commons license, unless indicated otherwise in a credit line to the material. If material is not included in the article's Creative Commons license and your intended use is not permitted by statutory regulation or exceeds the permitted use, you will need to obtain permission directly from the copyright holder. To view a copy of this license, visit http://creativecommons.org/ licenses/by/4.0/.

(C) The Author(s) 2019 